\title{
RESEARCH ARTICLE \\ Effects of Minerals on Growth of Silkworm, Bombyx mori L. and Their Impact on Cocoon Economic Parameters
}

\author{
K.A. MURUGESH*, R. ARUNA AND K. CHOZHAN \\ Department of Sericulture, Forest College \& Research Institute, Tamil Nadu Agricultural University, Mettupalayam - 641301
}

\begin{abstract}
The present study aimed at increasing the cocoon yield by fortifying the mulberry leaves with minerals such as zinc sulphate, magnesium sulphate and potassium chloride at different concentrations $(10,25,50,100$ and 200 ppm) and feeding them to the silkworm Bombyx mori L. The oral application of minerals through mulberry leaves to silkworm larva during lateage instars significantly improved its larval and cocoon economic parameters. Among the five concentrations tested, it was observed that the zinc sulphate @ 100 ppm, magnesium sulphate @ 200 ppm and potassium chloride @ 100 ppm registered significantly higher mature larval weight, effective rate of rearing (ERR), cocoon weight, pupal weight, shell weight and shell ratio than the control. Per os administration of minerals also significantly reduced the fifth instar larval duration of silkworm.
\end{abstract}

Keywords: Zinc; magnesium; potassium; silkworm; economic parameters.

\section{INTRODUCTION}

Mulberry silkworm, B. mori is an economically important insect in the silk industry due to its silk secreting ability. The silk production is reliant on the larval nutrition and nutritive value of mulberry leaves that plays a very effective role in the healthy growth and development of silkworm (Legay, 1958). The successful production of quality cocoons depends exclusively on the nutrition of silkworm. The silkworm requires certain essential sugars, proteins, amino acids and vitamins for its normal growth, survival and enhancement in the silk production. B. mori completely depends on mulberry leaves for its nutrient requirement since it is a monophagous insect (Ito, 1978). Mulberry leaves suitable as food for silkworms must contain several chemical constituents such as water (80\%), proteins (27\%), carbohydrates (11\%), mineral matters and vitamins (Koul, 1989).

Ito (1978) reported that the minerals present in mulberry leaves are required by silkworm larvae, but the quantity of minerals available in mulberry leaves is meagre, which depends on climatic condition, mulberry varieties and the type of fertilizers applied in the field (Sengupta et al.,1972). Mulberry leaves contain minerals up to 10 per cent and the silkworm larval body, in different ages, is composed of 28 percent by absorbed minerals (Ito, 1978). The nutritional status of mulberry leaves can be improved by enriching them with minerals and other nutrients.
Minerals are major constituents of the diets of silkworm, playing a vital role in osmotic pressure regulation of the intra and extracellular liquids and act as co-factors in different enzyme systems. The silk production parameters of silkworm depend on the larval nutrition and health status. In order to improve these production parameters, both in quantity and quality, a large number of minerals have been used. Many studies focusing on the effect of the minerals on silkworm were undertaken by various workers in different period of time (Sarker et al, 1995; Nirwani and Kaliwal, 1996; Hugar et al., 1998; Bhattacharya and Kaliwal, 2005; Islam et al., 2004; Khan et al., 2010).

The minerals particularly metals and their salt cations play a key role by acting as catalyst on the structural components of large molecules with a specific function which are indispensable for life. Ito (1967) reported that $B$. mori requires calcium, iron, magnesium, manganese, phosphorus, potassium and zinc for their growth and development. Murphy and Wyatt (1965) observed that magnesium is essential for complete activity of trehalose synthase. Zinc is an essential mineral and has an important role in RNA and DNA metabolism, in gene expression and is found in many classes of enzymes (Albergoni et al., 1980; Spurgeon et al., 2000; Kizilkaa, 2005).

Per os administration of zinc to silkworm larvae through mulberry leaves significantly increased the weight of larvae and silkgland. The mineral also brought down the mortality rate of silkworm and 
reduced the fifth instar larval duration (Balamani et al., 1995; Hugar and Kaliwal, 1999, 2002; Ashfaq et al., 2010).

Dasmahapatra et al. (1989) have reported that supplementation with cobalt, iodide, potassium, calcium chloride and potassium nitrate increased the protein, RNA and DNA content of the silk gland in the Nistari race of $B$. mori.

According to Hugar and Kaliwal (2002), the oral supplementation of zinc chloride to fourth and fifth instar silkworm larvae in different concentrations $(30,60$ and $90 \mu \mathrm{g} / \mathrm{mL})$ resulted in a significant increase in economic character namely larval weight, silk gland weight, cocoon weight, shell weight and cocooning percentage in lower concentration (30 $\mu \mathrm{g} / \mathrm{mL})$.

The oral application with potassium and magnesium chloride $(50,100$ and $150 \mu \mathrm{g} / \mathrm{mL})$ increased the fat body glycogen, protein, total lipids and haemolymph trehalose, protein of fifth instar larvae of $B$. mori due to enhanced enzymatic activity and metabolic process (Kaliwal and Bhattacharya, 2005). By keeping the above findings in mind, an attempt was made to study the impact of selected minerals on cocoon economic traits of silkworm.

\section{MATERIAL AND METHODS}

Experimenets were carried out to know the impacts of minerals such as zinc sulphate, magnesium sulphate and potassium chloride on growth of silkworm, B. mori and their impacts on economic parameters of cocoons. The methodology followed and materials used for the study are detailed below.

\section{i) Silkworm rearing}

The popular bivoltine Double Hybrid silkworm $[(\mathrm{CSR} 6 \times \mathrm{CSR} 26) \times(\mathrm{CSR} 2 \times \mathrm{CSR} 27)]$ was used for the investigations. Before commencement of silkworm rearing, the rearing house and appliances were thoroughly disinfected with 2.5 per cent chlorine dioxide +0.5 per cent slaked lime solution. After disinfection, the rearing house was kept closed in air tight conditions for $24 \mathrm{~h}$ and then opened to ward off the smell of chlorine completely (Dandin and Giridhar, 2014).

The silkworm rearing was taken up using mulberry leaves from V1 variety by following standard method (Krishnaswami et al., 1973). The larvae were fed three times a day and bed cleaning was done as per schedule. As prophylactic measure, the bed disinfectant was applied @ 5g/sq. ft bed area to prevent diseases, after bed cleaning (Baig and Pradip Kumar, 1987). The mature larvae were mounted using Netrika with the worm density of 50 Nos/ Sq. $\mathrm{ft}$. The cocoons were harvested six days after spinning separately replication wise and observations were recorded.

\section{ii) Preparation of stock solution}

A stock solution of 500 ppm was prepared by dissolving $500 \mathrm{mg}$ of the minerals viz., zinc sulphate, magnesium sulphate and potassium chloride individually in one liter of distilled water and the required concentrations viz., 10, 25, 50, 100 and 200 ppm were prepared by serial dilution.

\section{iii) Method of application}

Weighed quantities of fresh mulberry leaves were sprayed with an aqueous solution of the respective mineral. The leaves treated with mineral solution were shade dried for 30 minutes and fed on alternate days during third, fourth and fifth instars. One larval batch fed on mulberry leaves sprayed with distilled water was maintained along with untreated control for comparison.

\section{iv) Statistical analysis}

The experiments (two rearings) were conducted in Completely Randomized Design (CRD). Each treatment was replicated thrice with 50 larvae per replication. Statistical analysis of data was done using the method suggested by Panse and Sukhatme (1957) and means were compared with Duncun's Multiple Range Test (Duncun, 1955).

\section{RESULTS AND DISCUSSION}

The per os administration of minerals in the form of zinc sulphate, magnesium sulphate and potassium chloride at different concentrations viz., 10, 25, 50, 100 and 200 ppm to silkworm larvae during third, fourth and fifth instars significantly improved the growth of $B$. mori and economic parameters of cocoon.

\section{Effects of zinc sulphate on larval and cocoon parameters}

\section{a) Larval parameters}

The investigations revealed that fortification of mulberry leaves with zinc sulphate at different concentrations had a positive impact on the growth, development and economic parameters of silkworm (Table 1). Application of zinc sulphate @ 100 ppm significantly increased the larval weight to $3.20 \mathrm{~g}$ from $2.75 \mathrm{~g}$ which was found to be statistically superior over all other treatments. Here, the enhancement of larval weight is 16.36 per cent over the control. This was followed by 200, 50 and 25 ppm. The 10 ppm concentration registered lower larval weight of $2.77 \mathrm{~g}$ which was found to be statistically on par with the control. These observations fall more or less in line with the findings of Kaliwal and Hugar (2003) who reported that supplementation of zinc chloride to silkworm at varied concentrations of 30 , 
60 and $120 \mu \mathrm{g} / \mathrm{mL}$ to fourth and fifth instar resulted in increased larval weight. Further, Chamundeswari and Radhakrishnaiah (1994) also observed increased larval weight due to the biostimulating effect of zinc on the silkworm.

Table 1. Effect of Zinc sulphate on larval parameters of $B$. mori

\begin{tabular}{rrrr}
\hline $\begin{array}{c}\text { Concentrations } \\
(\mathbf{p p m})\end{array}$ & $\begin{array}{r}\mathbf{V} \text { instar larval } \\
\text { duration }(\mathbf{h})\end{array}$ & $\begin{array}{c}\text { Mature larval } \\
\text { weight }(\mathbf{g})\end{array}$ & ERR (\%) \\
\hline 10 & $167.80^{\mathrm{c}}$ & $2.77^{\mathrm{de}}$ & $83.05^{\mathrm{d}}$ \\
25 & $167.10^{\mathrm{c}}$ & $2.83^{\mathrm{d}}$ & $84.34^{\mathrm{c}}$ \\
50 & $166.00^{\mathrm{b}}$ & $2.90^{\mathrm{c}}$ & $86.31^{\mathrm{b}}$ \\
100 & $165.00^{\mathrm{a}}$ & $3.20^{\mathrm{a}}$ & $88.52^{\mathrm{a}}$ \\
200 & $165.25^{\mathrm{ab}}$ & $3.08^{\mathrm{b}}$ & $87.69^{\mathrm{a}}$ \\
Water spray & $168.60^{\mathrm{d}}$ & $2.78^{\mathrm{e}}$ & $82.84^{\mathrm{e}}$ \\
Control & $169.00^{\mathrm{d}}$ & $2.75^{\mathrm{e}}$ & $82.00^{\mathrm{e}}$ \\
$\mathbf{S E d}$ & 0.35 & 0.03 & 0.45 \\
$\mathbf{C D}(\mathbf{P}=\mathbf{0 . 0 5 )}$ & 0.70 & 0.06 & 1.00 \\
\hline
\end{tabular}

Values are mean of three replications and pooled mean of two silkworm crops.

Means followed by common letters are not significantly different at $5 \%$ level by DMRT $(P=0.05)$

Effective rate of rearing is the key indicator for successful silkworm rearing. In present investigation, highest ERR of 88.52 per cent was recorded in 100 ppm. However, this did not statistically differ from the ERR of larval batch treated with $200 \mathrm{ppm}$. The next better treatments were 50 (86.31\%), 25 (84.34 \%) and 10 (83.05 \%) ppm. The lowest ERR of 82.00 per cent was observed in the control. The improvement in ERR ranged from 1.29 to 7.95 per cent over the control. The higher ERR indirectly indicated the lesser susceptibility of the worms to dreaded diseases. These observations are strongly supported with the findings of Gokul (2015) who registered significantly higher ERR of 97.78 per cent in the larval batch treated with zinc chloride @ 200 ppm $(97.78 \%)$.

The fifth instar larval duration was also significantly altered due to the application of zinc sulphate. Statistically lowest fifth instar larval duration of $165 \mathrm{~h}$ was observed in $100 \mathrm{ppm}$ which was found to be statistically on par with 200 ppm (165.25 h). The larval batch fed with 50 and 25 ppm treated mulberry leaves did not differ statistically with each other. These results fall in line with the findings of Balamani et al. (1995); Hugar and Kaliwal (1999) and Ashfaq et al. (2010) who reported decreased fifth instar larval duration by supplementing minerals at higher concentration.

\section{b) Cocoon parameters}

Studies showed that enrichment of mulberry leaves with varied concentrations of zinc sulphate elucidated considerable positive influence on the cocoon related parameters of $B$. mori (Fig. 1). Highest cocoon weight of $1.76 \mathrm{~g}$ was registered in the larval batch fed with 100 ppm treated mulberry leaves. This treatment was followed by 200 (1.70 g), 50 (1.63 g), 25 (1.59 g) and 10 (1.56 g) ppm. Here, the treatments with 50 \& 25 ppm and 25 \& $10 \mathrm{ppm}$ were found to be statistically on par with each other. The least cocoon weight of $1.53 \mathrm{~g}$ was observed in the control. Increased cocoon weight was contributed by increased shell weight and pupal weight. Kaliwal and Hugar (2003) reported that fortification of mulberry leaves with zinc chloride and feeding them to fourth and fifth instars of silkworm at $120 \mu \mathrm{g} / \mathrm{mL}$ significantly increased the cocoon weight. Sivaprasad et al. (2012) reported that supplementation of zinc chloride at higher concentrations enhanced the cocoon yield and quality. These findings are in parity with the present observations.

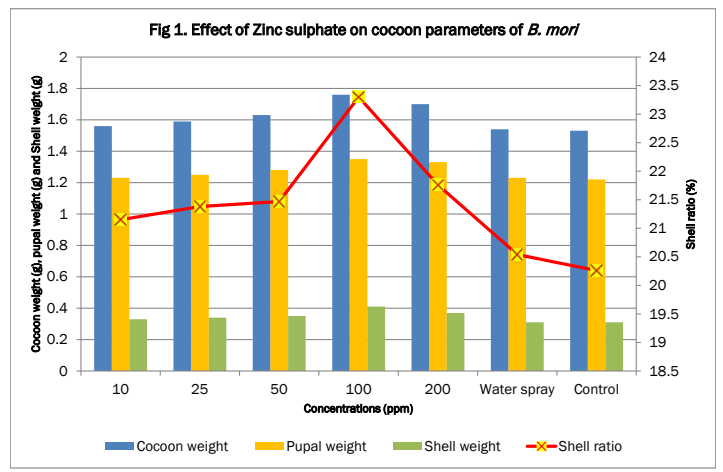

Exogenous application of minerals significantly improved the pupal weight. Maximum pupal weight of $1.35 \mathrm{~g}$ was registered in $100 \mathrm{ppm}$ which was found to be on par with 200 ppm (1.33 g) and significantly superior over all other treatments. Here, the larval batch fed with mulberry leaves treated with 50 \& 25 ppm and 25 \& 100 ppm concentrations did not differ statistically. The application of minerals might have led to excess amino group availability of fatty tissue in the pupal body and resulted in the heavier pupa. These observations can be corroborated with the findings of Gokul (2015) who reported that per os administration of zinc chloride at $200 \mathrm{ppm}$ to the fifth instar silkworm daily once in the morning resulted in the highest pupal weight of $1.62 \mathrm{~g}$.

Cocoon shell ratio is an important parameter that denotes the available silk filament in a cocoon, based on which the cocoon price is fixed. In the present experiment, the shell weight and shell ratio of $0.41 \mathrm{~g}$ and 23.30 percent, respectively were recorded in $100 \mathrm{ppm}$ treated larval batch. This was followed by 200 ppm which was found to be on par 
with $50 \mathrm{ppm}$. The treatment with $10 \mathrm{ppm}$ registered the shell weight and shell ratio of $0.33 \mathrm{~g}$ and 21.15 percent, respectively, however, these parameters were found to be statistically on par with the control. These results are in agreement with the earlier findings of Hugar et al. (1998); Ashfaq et al. (2010) and Kavitha et al. (2012), who have reported that application of zinc chloride either individually or in combination increased the shell weight and shell ratio significantly. The present observations were further supported by Kaliwal and Hugar (2003) who found that supplementation of zinc chloride to lateage silkworm at 30, 60 and $120 \mu \mathrm{g} / \mathrm{mL}$ resulted in increased shell weight and shell ratio.

\section{Effects of magnesium sulphate on larval and cocoon parameters}

\section{a) Larval parameters}

Supplementation of minerals with mulberry leaves invariably increased the larval parameters over the untreated control (Table 2). Per os application of magnesium sulphate @ 200 ppm significantly enhanced the larval weight ( $3.30 \mathrm{~g}$ ) than all the concentrations tested, which was followed by 100 ppm (3.21 g). The treatments having 50 and $25 \mathrm{ppm}$ were found to be on par with each other. The lowest mature larval weight of $2.83 \mathrm{~g}$ was registered in the control. This result is strengthened by the findings of Ashfaq et al. (1998) and, Hugar and Kaliwal (2002), who observed the increased larval weight by supplementation of minerals to the fifth instar. Further, the findings of Gokul (2015) who registered higher fifth instar larval weight, when the silkworm larvae were provided with mulberry leaves sprayed with different minerals, is also in line with the present observation.

Table 2: Effect of Magnesium sulphate on larval parameters of $\mathbf{B}$. mori

\begin{tabular}{rrrr}
\hline $\begin{array}{c}\text { Concentrations } \\
\text { (ppm) }\end{array}$ & $\begin{array}{r}\text { V instar larval } \\
\text { duration (h) }\end{array}$ & $\begin{array}{r}\text { Mature larval } \\
\text { weight (g) }\end{array}$ & ERR (\%) \\
\hline 10 & $169.17^{\mathrm{c}}$ & $2.96^{\mathrm{d}}$ & $84.69^{\mathrm{c}}$ \\
25 & $168.32^{\mathrm{b}}$ & $3.06^{\mathrm{c}}$ & $84.62^{\mathrm{c}}$ \\
50 & $168.15^{\mathrm{b}}$ & $3.08^{\mathrm{c}}$ & $85.18^{\mathrm{c}}$ \\
100 & $167.40^{\mathrm{a}}$ & $3.21^{\mathrm{b}}$ & $86.62^{\mathrm{b}}$ \\
200 & $167.10^{\mathrm{a}}$ & $3.30^{\mathrm{a}}$ & $88.75^{\mathrm{a}}$ \\
Water spray & $170.0^{\mathrm{d}}$ & $2.87^{\mathrm{e}}$ & $83.68^{\mathrm{d}}$ \\
Control & $170.25^{\mathrm{d}}$ & $2.83^{\mathrm{e}}$ & $83.10^{\mathrm{d}}$ \\
$\mathbf{S E d}$ & 0.26 & 0.04 & 0.40 \\
$\mathbf{C D}(\mathbf{P}=\mathbf{0 . 0 5 )}$ & 0.50 & 0.08 & 0.80 \\
\hline
\end{tabular}

Values are mean of three replications and pooled mean of two silkworm crops.

Means followed by common letters are not significantly different at $5 \%$ level by DMRT $(\mathrm{P}=0.05)$
Significantly superior ERR of 88.75 percent was recorded in 200 ppm which was followed by 100 ppm. Here, the enhancement in ERR is 6.80 percent over the control. The larval batch treated with 50 , 25 and $10 \mathrm{ppm}$ of zinc sulphate did not differ statistically. The least ERR of 83.10 percent was observed in the control. This result falls in line with Balamani et al. (1995) and Ashfaq et al. (2010) who reported increased ERR due to supplementation of minerals at higher concentrations.

The application of magnesium sulphate significantly altered the fifth instar larval duration. The treatment with 200 ppm recorded the lowest larval duration of $167.10 \mathrm{~h}$ which was found to be statistically in parity with 100 ppm (167.40 h). The next better treatments such as 50 and 25 ppm were also found to be statistically on par with each other. The fifth instar larval duration of larval batch fed with untreated mulberry leaves lasted for 170.25 h. These observations can be corroborated with Hugar and Kaliwal (1999) and Ashfaq et al. (2010) who reported decreased fifth instar larval duration by feeding the silkworm larvae through minerals fortified mulberry leaves.

\section{b) Cocoon parameters}

The oral administration of magnesium sulphate resulted in improved the cocoon related parameters (Fig. 2). Among different concentrations tested, 200 ppm recorded maximum cocoon weight of $1.72 \mathrm{~g}$ which showed statistical superiority over all other treatments. The next better concentrations namely 100 (1.64 g) \& 50 (1.58 g) and 25 (1.56 g) \& 10 (1.54 g) ppm were found to be statistically on par with each other. The cocoon weight ranged from 3.36 to 15.43 percent. These observations fall in agreement with Kaliwal and Bhattacharya (2005), who revealed that the dietary supplementation of silkworm larvae with 50, 100 and $150 \mu \mathrm{g} / \mathrm{mL}$ of potassium and magnesium chloride resulted in increased cocoon weight due to the synergetic effect.

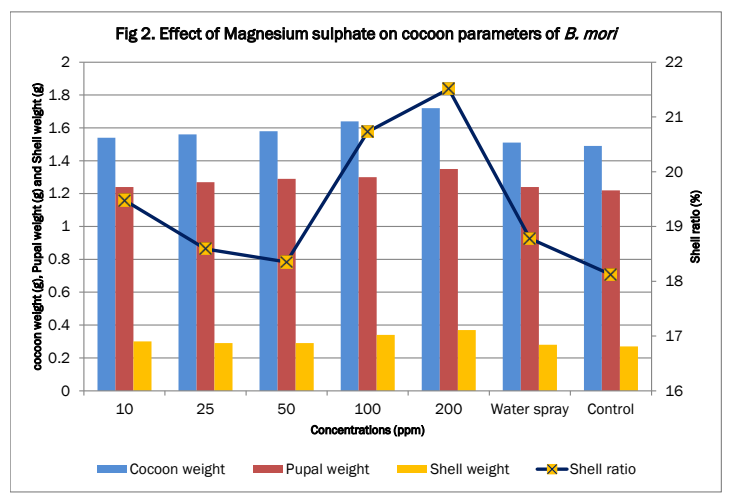

The highest pupal weight of $1.35 \mathrm{~g}$ was observed in the larval batch applied with $200 \mathrm{ppm}$ of magnesium sulphate. The concentrations with 100 (1.30 g), 50 (1.29 g) and 25 (1.27 g) ppm were found

$107 \mid 10-12$ | 4 
to be on par with each other. Significantly least pupal weight of $1.21 \mathrm{~g}$ was recorded in the control. The improvement in pupal weight ranges from 1.64 to 10.66 percent due to supplementation of mineral. The exogenous supplementation of magnesium sulphate would have resulted in the availability of excess amino group in the fatty tissue of pupal body and formation of heavier pupa. This was, further, supported by Narasimhana (1988) and Hugar and Kaliwal (1999).

The highest shell weight and shell ratio of $0.37 \mathrm{~g}$ and 21.51 percent, respectively were recorded in 200 ppm which was found to be statistically on par with 100 ppm (0.34 g and $20.73 \%$, respectively). Here, the increase in shell weight and shell ratio was 37.09 and 14.48 percent, respectively. This was followed by 50 ppm (0.29 g and $18.35 \%$, respectively) and 25 ppm ( 0.29 g and $18.59 \%$, respectively) which did not differ statistically. The lowest shell weight and shell ratio were recorded in the control. The nutritional studies on silkworm revealed that mineral salts, particularly magnesium chloride, calcium chloride and potassium chloride showed positive trends with reference to silkworm cocoon weight, shell weight and shell ratio (Chakraborti and Medda, 1978; Bhattacharya and Kaliwal, 2005). These findings fall more or less in line with the present observations.

\section{Effects of potassium chloride on larval and cocoon parameters}

\section{a) Larval parameters}

Feeding the silkworm larvae with mulberry leaves sprayed with potassium chloride at different concentrations significantly improved larval parameters (Table 3 ). The mature larval weight was maximum in $100 \mathrm{ppm}$ (3.34 g). Here, the enhancement in the mature larval weight is 8.79 percent over the control. The next better concentrations were in the order of $200,50,25$ and $10 \mathrm{ppm}$. Supplementation of potassium nitrate and potassium iodide resulted in increased larval weight (Chakraborty and Medda, 1978; Subburathinam and Sulochanachetty, 1991). Fortification of mulberry leaves with potassium permanganate and feeding them to silkworm larvae resulted in increased larval weight (Bhattacharya and Kaliwal, 2004). These findings can be corroborated with the present observations.

The ERR of 88.72 percent was registered in 100 ppm. This was followed by 200 and 50 ppm which were found to be on par with each other. The $10 \mathrm{ppm}$ concentration recorded a lower ERR of 83.02 per cent and did not differ statistically with the control $(82.50 \%)$. This observation falls more or less in line with the findings of Kochi and Kaliwal (2005), according to them, the oral supplementation of a mineral mixture of potassium bromide and nickel sulphate to silkworm, CSR2, CSR4 and CSR2 x CSR4 with different concentrations viz., 70, 110 and 160 $\mu \mathrm{g} / \mathrm{mL}$ resulted significant increase in ERR.

Table 3: Effect of Potassium chloride on larval parameters of B. mori

\begin{tabular}{rrrr}
\hline $\begin{array}{c}\text { Concentrations } \\
\mathbf{( p p m )}\end{array}$ & $\begin{array}{r}\text { V instar larval } \\
\text { duration (h) }\end{array}$ & $\begin{array}{c}\text { Mature larval } \\
\text { weight }(\mathbf{g})\end{array}$ & ERR (\%) \\
\hline 10 & $168.90^{\mathrm{c}}$ & $3.14^{\mathrm{d}}$ & $83.02^{\mathrm{e}}$ \\
25 & $168.55^{\mathrm{c}}$ & $3.19^{\mathrm{cd}}$ & $84.31^{\mathrm{d}}$ \\
50 & $167.83^{\mathrm{b}}$ & $3.23^{\mathrm{bc}}$ & $86.51^{\mathrm{c}}$ \\
100 & $166.50^{\mathrm{a}}$ & $3.34^{\mathrm{a}}$ & $88.72^{\mathrm{a}}$ \\
200 & $167.42^{\mathrm{b}}$ & $3.28^{\mathrm{b}}$ & $87.41^{\mathrm{b}}$ \\
Water spray & $169.60^{\mathrm{d}}$ & $3.09^{\mathrm{e}}$ & $82.95^{\mathrm{e}}$ \\
Control & $169.87^{\mathrm{d}}$ & $3.07^{\mathrm{e}}$ & $82.50^{\mathrm{e}}$ \\
$\mathbf{S E d}$ & 0.34 & 0.03 & 0.52 \\
$\mathbf{C D}(\mathbf{P}=\mathbf{0 . 0 5 )}$ & 0.65 & 0.05 & 1.05 \\
\hline
\end{tabular}

Values are mean of three replications and pooled mean of two silkworm crops.

Means followed by common letters are not significantly different at $5 \%$ level by DMRT $(P=0.05)$

The least fifth instar larval duration of $166.50 \mathrm{~h}$ was noted in the larval batch fed by mulberry leaves fortified with $100 \mathrm{ppm}$ potassium chloride which was found to be superior over all other treatments tested. The concentrations viz., $200 \& 50$ ppm, and $25 \& 10$ ppm did not differ significantly among themselves. This observation can be supported by the findings of Gokul (2015), who observed that the feeding of silkworm larvae with mulberry leaves supplemented with potassium chloride @ 200 ppm from first day of fifth instar to spinning significantly decreased the larval duration to $165 \mathrm{~h}$ from $171 \mathrm{~h}$ in the control.

\section{b) Cocoon parameters}

Investigations revealed that fortification of mulberry leaves with potassium chloride at varied concentrations elucidated significant improvement on the cocoon characteristics of silkworm (Fig. 3). The maximum cocoon weight of $1.76 \mathrm{~g}$ was observed in the larval batch fed by mulberry leaves sprayed with $100 \mathrm{ppm}$ of potassium chloride. Here, the cocoon weight increased by 15.03 percent over the control due to the application of the mineral. This treatment was followed by 200 (1.71 g), 50 (1.70 $\mathrm{g})$, and 25 (1.67 g) ppm which were found to be on par with each other. The minimum cocoon weight of $1.53 \mathrm{~g}$ was observed in the control. Oral supplements of potassium permanganate resulted in increased cocoon weight of B. mori (Bhattacharya and Kaliwal, 2004). Per os application of mineral mixture having potassium bromide and nickel sulphate to fifth instar bivoltine silkworm races and hybrids with different 
concentrations resulted significant increase in cocoon weight (Kochi and Kaliwal (2005). Both the above findings are in parity with the present observations.

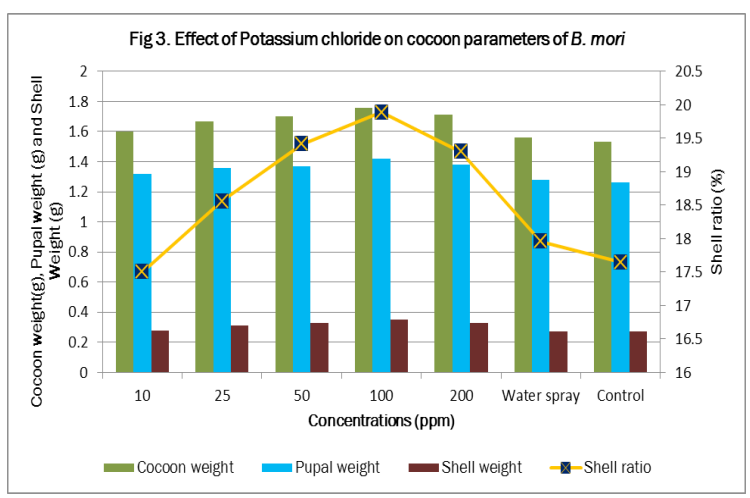

Significantly highest pupal weight of $1.42 \mathrm{~g}$ was observed in $100 \mathrm{ppm}$. The next better treatments viz., 200, 50 and 25 ppm were found to be statistically on par with each other. The increment over the control ranged from 4.76 to 12.69 percent. The same trend was observed by Gokul (2015), who registered the highest pupal weight of $1.59 \mathrm{~g}$ when the fifth instar larvae were fed with mulberry leaves fortified with potassium chloride @ 200 ppm.

The shell weight and shell ratio of $0.35 \mathrm{~g}$ and 19.89 percent, respectively were recorded in 100 ppm. However, this was found to be on par with 50 ppm $(0.33$ gand $19.41 \%$, respectively $)$ and $200(0.33$ g and $19.30 \%$, respectively) ppm. The enhancement in shell weight and shell ratio was 29.63 and 12.69 percent, respectively over the control. Here, the concentration of $10 \mathrm{ppm}$ was found to be on par with the control. The present observation is in parity with the findings of Chakraborty and Medda (1978) and, Subburathinam and Sulochanachetty (1991) who recorded that the supplementation of potassium nitrate and potassium iodide to silkworm larvae resulted in increased shell weight and shell ratio.

\section{CONCLUSION}

The present study crystal clearly showed that per os administration of mineral viz., zinc sulphate, magnesium sulphate or potassium chloride at 100 ppm, 200 ppm or 100 ppm, respectively during first \& third days of third \& fourth instars and, first, third \& fifth days of fifth instar of silkworm, B. mori significantly improved the biological traits of larvae as well as economic traits of cocoons.

\section{Author contributions}

Idea conceptualization - KAM; ExperimentsKAM; Writing-original draft- KAM; Writing- reviewing \&editing - KAM, RA, KC.

\section{REFERENCES}

Arai, N. and T. Ito. 1967. Nutrition of the silkworm, Bombyx mori -XVI. Quantitative requirements for essential amino acids. Bulletin sericulture Experiments Station Japan, 21: 373-384.

Ashfaq, M., N. Ahmad and A. Ali. 1998. Effect of optimum doses of nitrogen, potassium, calcium and copper on silkworm, Bombyx mori L. development and silk yield. South Pacific Stisy., 18(2): 47-50.

Ashfaq, M., W. Afzal and M. Asif Hanif. 2010. Effect of $\mathrm{Zn}$ (II) deposition in soil on mulberry-silk worm food chain. African Journal of Biotechnology, 9(11): 1665-1672.

Baig, M. and T. Pradipkumar. 1987. Silkworm diseases and pests. In: Appropriate Sericulture Technique, M. S. Jolly (Ed.), CSR \& TI, Mysore, India. pp.107144.

Balamani, R., S.P. Prince, W. Subburam and V Subburam. 1995. Effect of zinc on the nutritional indices, economic characters of cocoon and quality of silk ob Bombyx mori L. Indian J., Seric., 34: 69-71.

Bhattacharya, A. and B.B. Kaliwal. 2004. Influence of mineral potassium permanganate on the biochemical constituents in the fat body and haemolymph of the silkworm, B. mori L. Int. J. Indust. Entomol., 9: 131-135.

Bhattacharya, A. and B.B. Kaliwal. 2005. Influence of the mineral, potassium permanganate on the economic parameters of the silkworm, Bombyx mori L. National Conference on Sericulture for Global Competitiveness. pp. 334-336.

Chakraborti, M.K. and A.K. Medda. 1978. Effect of cobalt chloride on economic parameters of silkworm (Bombyx mori L.) Nistari Race. Sci. and Cult., 44: 406-408.

Chamundeswari, P. and K. Radhakrishnaiah 1994. Effect of zinc and nickel on the larval and cocoon characters of the silkworm, Bombyx mori L. Sericologia, 34: 327-330.

Dandin, S.B. and K. Gridhar. 2014. Handbook of Sericulture Technologies. Central Silk Board, Bangalore. pp. 315-325.

Dasmahapatra, A.K., M.K. Chakrabarti and A.K. Medda. 1989. Effect of potassium iodide, cobalt chloride, calcium chloride and potassium nitrate on protein, RNA and DNA contents of silk gland of silkworm (Bombyx mori L.), Nistari race. Sericologia, 29: 355-359.

Duncan, D.B. 1955. Multiple range and multiple F. tests. Biometrics, 11:1-42.

Gokul, M. 2015. Effect of exogenous supplementation of amino acids and minerals on economic traits of silkworm, Bombyx mori L. M.Sc. (Seri.) Thesis, Tamil Nadu Agricultural University, Coimbatore. pp.101.

Hugar, I. and B.B. Kaliwal. 1999. Effect of zinc chloride on some economic parameters of the bivoltine silkworm. Bombyx mori L. Bull. Sericult. Res. 10: 35-42. 
Hugar, I. and B.B. Kaliwal. 2002. Effect of zinc chloride economical traits of the bivoltine silkworm. Bombyx mori L. Int. J. Indust. Entomol, 5: 75-79.

Hugar, I. and B.B. Kaliwal. 2002. Effect of zinc chloride economical traits of the bivoltine silkworm. Bombyx mori L. Int. J. Indust. Entomol, 5: 75-79.

Islam, R., Ohayed, A., Paul, D.K., Sultana, S, Banu, A.K and Islam, M.R., 2004. Effect of salt, nickel chloride supplementation on the growth of silkworm, Bombyx mori L. (Lepidoptera: Bombycidae), J. Bio. Scis. 4(2): 170-172.

Ito, T. 1978. Silkworm nutrition In: The Silkworm-An Important Laboratory Tool, Tazima, Y. Kodansha (Ed.) Ltd., Tokyo, pp .121-153.

Kaliwal, B.B. and A. Bhattacharya 2005. Synergetic effects of potassium and magnesium chloride on biochemical contents of the silkworm, Bombyx mori L. Caspian Journal of Environmental Sciences, 3: 1-7.

Kaliwal, B.B. and I.I. Hugar. 2003. Effect of zinc chloride on commercial traits of the bivoltine silkworm, Bombyx mori L. Int. J. Indust. Entomol., 5(2): 75-79.

Kavitha, S., S. Sivaprasad, S. Bano and K. Yellama. 2012. Effect of zinc chloride and zinc sulphate on the silkworm, Bombyx mori growth tissue proteins and economic parameters of sericulture. The Bioscan, 7(2): 189-195.

Khan, M. A. Akram, W., Ashfaq, M. and Khan, A. 2010. Effects of optimum doses of nitrogen, phosphorus, potassium and calcium on silkworm, Bombyx mori L., growth and yield. Entomological Research. 40(6):285 - 289.

Kochi S.C. and B.B. Kaliwal. 2005. Synergetic effect of minerals mixture of potassium bromide and nickel sulphate on the economic traits of CSR2, CSR4 and CSR $2 \times$ CSR 4 crossbreed races of the silkworm, Bombyx mori L. Int. J. Indust. Entomol., 10(2): 107-117.

Koul, A. 1989. Relationship among leaf consumption, body weight and silk production in Bombyx mori L. Agric. Sci. Digest., 9 (4): 208-209.
Krishnaswami, S., M.N. Narasimhanna, S.K. Suryanarayana and S. Kumaraj. 1973. Sericulture manual 2, Silkworm rearing. FAO, Agricultural Services Bulletin, Rome. 131p.

Legay, J.M. 1958. Recent advances in silkworm nutrition. Annual Review of Entomology, 3: 76-86.

Murphy, T.A. and G. R. Wyatt. 1965. The enzymes of glycogen and trehalose synthesis in silk moth fat body. J. Biol. Chem., 240 (4):1500-1508.

Narasimhanna, 1988. Manual on silkworm egg production. Central silk board, Bangalore, India. 64p.

Nirwani R.B. and B.B. Kaliwal. 1996. Increase of silk production and quantitative changes of carbohydrate and protein in the fat body and haemolymph after feeding potassium sulphate to bivoltine Bombyx mori L. Sericologia. 36: 523-530.

Panse, V.G. and Sukhatme. 1957. Statistical Methods for Agricultural Workers, ICAR, New Delhi. 328p.

Sarker A., M. Haque, M. Rab and N. Absar. 1995. Effects of feeding mulberry (Morus sp.) supplemented with different nutrients to silkworm, Bombyx mori L. Curr. Sci., 69: 185-188.

Sengupta, K., B.D. Singh and J.C. Mustafi. 1972. Nutrition of silkworm Bombyx mori L. Studies on the enrichment of mulberry leaf with various sugars, proteins, amino acids and vitamins for vigorous growth of worms and increased cocoon crop production. Indian Journal of Sericulture, 11: 11-19.

Sivaprasad, S., S. Kavitha, Bano Saidulla and K. Yellemma. 2012. Effect of zinc chloride and zinc sulphate on the silkworm, Bombyx mori growth tissue proteins and economic parameters of sericulture. Journal of Life Science, 7(2): 189-195.

Subburathinam, K.M. and J. Sulochanachetty. 1991. Effect of fortification of mulberry leaves with minerals to silkworm, Bombyx mori L. Indian J. Seric., 30: 121-123. 